Newton, B. A. (1957). J. gen. Microbiol. 17, 708-717

\title{
Nutritional Requirements and Biosynthetic Capabilities of the Parasitic Flagellate Strigomonas oncopelti
}

\author{
By B. A. NEWTON \\ Medical Research Council Unit for Chemical Microbiology, \\ Biochemical Laboratory, University of Cambridge
}

SUMMARY : A study of the nutritional requirements of the trypanosomid flagellate Strigomonas (Herpetomonas) oncopelti has led to the development of a chemically defined growth medium containing methionine, thiamine, nicotinamide, $p$-aminobenzoic acid, glucose, salts and trace metals. Fractionation and analysis of organisms grown in this defined medium supplemented with trace amounts of various ${ }^{14} \mathrm{C}$-labelled substrates has thrown light upon the ability of growing organisms to utilize carbon derived from glucose, acetate, a number of amino acids, purines and pyrimidines for the synthesis of cellular components.

Metabolic studies of the Trypanosomidae have in general been confined to studies of catabolism and there is little known about the pathways of biosynthesis in these organisms. The development of a simple chemically defined growth medium for the parasitic flagellate Strigomonas (Herpetomonas) oncopelti (Newton, 1956a) permits a detailed study of the biosynthetic capabilities of an actively growing trypanosomid.

Strigomonas oncopelti was first isolated in bacteria-free culture by Noguchi \& Tilden in 1926; it is parasitic in the digestive tract of hemipterous insects and in latex plants. Lwoff (1937) reported that $S$. oncopelti can be cultivated in certain peptones or in alkaline hydrolysates of silk when these are supplemented with thiamine; he also observed that this organism, in contrast to other members of the Trypanosomidae, does not require haematin for growth in peptone media. This latter finding has recently been confirmed by Nathan, Cowperthwaite, Carsted \& Hutner (1955), but these workers found, unexpectedly, that their strain of $S$. oncopelti did require haematin for growth in a chemically defined medium containing seventeen amino acids, a complete vitamin supplement and a selection of nucleic acid derivatives. The strain of $S$. oncopelti used for the work described in the present paper did not require haematin in either peptone or the defined media. Studies of the catabolic metabolism of $S$. oncopelti were recently described by Clausen (1955) and Ryley (1955) and the latter author pointed out that there are striking similarities between this organism and Trypanosoma lervisi, especially with regard to their carbohydrate metabolism. The present paper describes the nutritional requirements of $S$. oncopelti and the ability of actively growing organisms to utilize various ${ }^{14} \mathrm{C}$-labelled substrates for the synthesis of cellular components; some of these results have been reported in a preliminary communication (Newton, 1956b). 


\section{METHODS}

Organism. A bacteria-free culture of Strigomonas (Herpetomonas) oncopelti was kindly supplied by Dr Muriel Robertson, F.R.S. (Lister Institute of Preventive Medicine, London).

Conditions of cultivation. Stock cultures were maintained in $5 \mathrm{ml}$. volumes of $3 \%(w / v)$ Evans bacteriological peptone containing $0.5 \%(w / v)$ sodium chloride and $0.5 \%(\mathrm{w} / \mathrm{v})$ glucose; initial $\mathrm{pH} \mathrm{7.4}$. The medium was sterilized by autoclaving at $15 \mathrm{lb}$./sq.in. for $20 \mathrm{~min}$. Cultures were incubated at $25^{\circ}$ and subcultured every other day.

Growth tests. The nutritional requirements of Strigomonas oncopelti were determined in defined media according to the general method of Gladstone (1937). A 'complete' defined medium was prepared containing glucose, salts and trace metals in the amounts shown in Table 1 and in addition 18 amino acids (glycine, L-aspartic and L-glutamic acids, L-arginine, DL-methionine, L-lysine, DL-threonine, L-proline, DL-tryptophan, L-tyrosine, L-cysteine, DL-serine, DL-phenylalanine, L-histidine, I-valine, DL-alanine, L-leucine and DL-isoleucine) at a final concentration of $200 \mu \mathrm{g}$. $\mathrm{L}$-isomer $/ \mathrm{ml}$; p purines and

Table 1. Minimal defined growth medium for Strigomonas oncopelti

$\begin{array}{lrll} & \text { mg. } & & \text { g. } \\ \text { Methionine } & 200 \cdot 0 & \text { Glucose } & 5 \cdot 0 \\ \text { Thiamine } & 1 \cdot 0 & \mathrm{NH}_{4} \mathrm{Cl} & 5 \cdot 0 \\ \text { Nicotinamide } & 1 \cdot 0 & \mathrm{Na}_{8} \mathrm{HPO}_{4} .2 \mathrm{H}_{2} \mathrm{O} & 0 \cdot 25 \\ p \text {-Aminobenzoic acid } & 1 \cdot 0 & \mathrm{KH}_{2} \mathrm{PO}_{4} & 0 \cdot 08 \\ & & \mathrm{NaCl} & \mathbf{0 \cdot 0} \\ & & \mathrm{KCl} & 0 \cdot 42\end{array}$

Trace metal solution*, $10 \mathrm{ml}$.

Glass-distilled water to 1 l. Initial $\mathrm{pH}$ value $7 \cdot 2$.

Medium sterilized by autoclaving at $10 \mathrm{lb}$./sq.in. for $10 \mathrm{~min}$.

* Trace metal solution: $\mathrm{MgSO}_{4} .7 \mathrm{H}_{2} \mathrm{O}, 20$ g.; $\mathrm{FeSO}_{4}, 0.5$ g.; $\mathrm{ZnSO}_{4} .7 \mathrm{H}_{2} \mathrm{O}, 0.5$ g.; $\mathrm{MnSO}_{4} .3 \mathrm{H}_{2} \mathrm{O}, 0.5 \mathrm{~g}$.; $\mathrm{CuSO}_{4} .5 \mathrm{H}_{2} \mathrm{O}, 0 \cdot 5 \mathrm{~g}$. made up to 11 . in $0 \cdot 1 \mathrm{~N}-\mathrm{H}_{2} \mathrm{SO}_{4}$.

pyrimidines (adenine, xanthine, hypoxanthine, guanine, thymine, cytosine, uracil) at a final concentration of $20 \mu \mathrm{g} . / \mathrm{ml}$. and growth factors (thiamine, pyridoxin, riboflavin, calcium pantothenate, nicotinic acid, biotin, $p$-aminobenzoic acid) at a final concentration of $1 \mu \mathrm{g} . / \mathrm{ml}$. except for biotin which was used at $0.001 \mu \mathrm{g} . / \mathrm{ml}$. Further batches of medium were prepared to test the effect of omission of the above components either singly or in groups. Organisms to be used as inocula in growth tests were grown in the complete defined medium for $24 \mathrm{hr}$. at $25^{\circ}$ and were washed three times in the medium to be tested; a standard inoculum of $c .2 \times 10^{5} \mathrm{organisms} / \mathrm{ml}$. medium was used in all cases and the amount of growth was measured by counting the organisms at $24 \mathrm{hr}$. intervals during incubation at $25^{\circ}$.

Counting the organisms. Samples $(1 \mathrm{ml}$.) of cultures were fixed with $0.05 \mathrm{ml}$. $40 \%(w / v)$ formaldehyde in water. Four counts were made on each sample in a Neubauer haemocytometer, a minimum of $\mathbf{3 0 0}$ organisms being counted in each case. 
Conditions of growth for incorporation experiments. Five ml. of a $48 \mathrm{hr}$. culture in the minimal defined medium (Table 1), or in modifications of this medium to be described below, were used as inoculum for $50 \mathrm{ml}$. lots of the same medium contained in $150 \mathrm{ml}$. conical flasks, to which had been added trace amounts of ${ }^{14} \mathrm{C}$-labelled substrates; the initial count of organisms was c. $15 \times 10^{5} / \mathrm{ml}$. in all experiments. An experimental growth period of $24 \mathrm{hr}$. was used, resulting in a 2 - to 3 -fold increase in number of organisms.

Harvesting and fractionation of organisms. The organisms were harvested by centrifugation and washed three times with a saline solution $(0.9 \%, w / v$, $\mathrm{NaCl}+\mathbf{0} \cdot 42 \%, \mathrm{w} / \mathrm{v}, \mathrm{KCl}$ ) before fractionation. The fractionation procedure adopted was essentially the same as that described by McQuillen \& Roberts (1954): $5 \%(\mathrm{w} / \mathrm{v})$ trichloroacetic acid (TCA) for $1 \mathrm{hr}$. at $5^{\circ}$ extracts acidsoluble constituents (fraction 1); $75 \%$ (v/v) ethanol in water for $30 \mathrm{~min}$. at $50^{\circ}$ extracts ethanol-soluble protein and some lipid; further extraction with ether $(1 \mathrm{vol})+.75 \%(\mathrm{v} / \mathrm{v})$ ethanol in water $(1 \mathrm{vol}$.$) for 15 \mathrm{~min}$. at $37^{\circ}$ removes further fatty material and protein. The ethanol and ether + ethanol extracts are combined, addition of equal volumes of ether and water then results in division of two phases: ethanol-soluble protein (fraction 2) remains in the aqueous phase and the lipid (fraction 3 ) enters the ether phase; finally, $5 \%$ (w/v) TCA for $15 \mathrm{~min}$. at $100^{\circ}$ extracts nucleic acids (fraction 4). The residue after ether washing represents the main protein fraction of the organisms

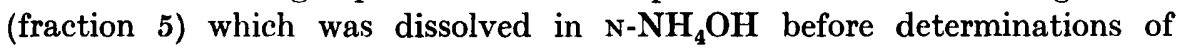
radioactivity.

Radioactivity measurements. Samples $(0 \cdot 3 \mathrm{ml}$.) of each of fractions $1-5$, in duplicate, were placed on polythene disks of surface area $2 \mathrm{sq.cm}$. One drop of $0.2 \%(\mathrm{w} / \mathrm{v})$ cetyltrimethylammonium bromide (CTAB) and one drop of $1 \%(\mathrm{w} / \mathrm{v})$ polyvinyl alcohol were added to each sample and the preparations dried in vacuo. In this way films of less than $1 \mathrm{mg} . / \mathrm{sq} . \mathrm{cm}$. were obtained and self-absorption was less than $5 \%$. The ${ }^{14} \mathrm{C}$ content of the dried preparations was estimated by use of an end-window Geiger-Muller tube and scaler in the conventional manner.

Investigation of major cell fractions. Fraction 1, the cold TCA-soluble fraction, was extracted with ether to remove TCA and chromatographed in the solvent systems described below. Fraction 2, ethanol-soluble protein, was hydrolysed in $6 \mathrm{~N}-\mathrm{HCl}$ in sealed tubes for $16 \mathrm{hr}$. at $105^{\circ}$, and the hydrolysates, after removal of acid, run on two-dimensional chromatograms with secbutanol + formic acid and phenol + ammonia as solvents. Fraction 3 , the lipid fraction, was hydrolysed in $6 \mathrm{~N}-\mathrm{HCl}$ for $48 \mathrm{hr}$. at $105^{\circ}$ in sealed ampoules, the hydrolysates chilled and filtered, the filtrates evaporated to dryness in vacuo and, after removal of acid, chromatographed in $n$-butanol + morpholine solvent. Fraction 4, the nucleic acid fraction, was hydrolysed in $72 \%(w / w)$ perchloric acid at $100^{\circ}$ for $1 \mathrm{hr}$. and, after dilution with an equal volume of water, the hydrolysate was chromatographed in isopropanol $+\mathrm{HCl}$ solvent. Fraction 5 was treated in the same way as fraction 2.

Chromatography. One-dimensional descending and two-dimensional ascending chromatograms were run on Whatman no. 1 paper. Four solvents 
were used: $s e c$-butanol, $70 \%$ (v/v), formic acid, $10 \%(\mathrm{v} / \mathrm{v})$, water, $20 \%(\mathrm{v} / \mathrm{v})$; phenol crystals, $80 \mathrm{~g}$., ammonium hydroxide (sp.gr. $\mathbf{0} \cdot 880$ ), $\mathbf{0 . 3} \mathrm{ml}$., water, $20 \mathrm{ml}$.; isopropanol, $68 \%$ (v/v), hydrochloric acid (sp.gr. 1.18), 17.6\% (v/v), water, 14.4\% (v/v); $n$-butanol, $75 \%(\mathrm{v} / \mathrm{v})$, morpholine, $25 \%(\mathrm{v} / \mathrm{v})$. Radioautographs of chromatograms were prepared on Ilford (Industrial G) X-ray film.

Paper electrophoresis. Arginine, histidine and lysine were not well separated by two-dimensional chromatography but complete separation was obtained, after elution from chromatograms, by electrophoresis on paper buffered with 0.05 M-sodium carbonate + sodium bicarbonate buffer, $\mathrm{pH} 9.6$; a potential of $800 \mathrm{~V}$ d.c. was applied for $2 \frac{1}{2} \mathrm{hr}$. (Dr R. Davies, private communication).

Isotopes. ${ }^{14} \mathrm{C}$-labelled glucose, acetate and amino acids were obtained from the Radiochemical Centre, Amersham. Purines and pyrimidines were worked up from residues of Chlorella grown in ${ }^{14} \mathrm{CO}_{2}$ and supplied by the Radiochemical Centre, Amersham.

\section{RESULTS}

\section{Nutritional requirements of Strigomonas oncopelti}

Preliminary growth experiments showed that the complete defined medium supported the growth of organisms transferred from $3 \%(w / v)$ peptone medium; further experiments were designed to determine the minimal growth requirements for Strigomonas oncopelti.

Amino acid requirements. The only amino acid present in the complete growth medium which was found to be essential for growth was methionine. In the absence of all other amino acids the concentration of methionine required for optimal growth was found to be $200 \mu \mathrm{g}$. DL-methionine/ml. Methionine could be replaced by: cystathionine alone; by homocysteine+ a suitable 1-carbon source such as formate, glycine, serine or phosphoserine but not choline; by threonine + serine + cysteine; in this latter case the cysteine could be replaced by cysteine sulphinic acid but not by taurine, cysteic acid or an inorganic sulphur source.

Growth factor requirements. Thiamine, nicotinic acid and $p$-aminobenzoic acid were essential for growth when the only amino acid present was methionine.

Purine and pyrimidine requirements. No absolute requirement for purines or pyrimidines was found, but adenine $(20 \mu \mathrm{g} . / \mathrm{ml}$.) could replace $p$-aminobenzoic acid.

\section{Incorporation experiments}

Utilization of acetate for synthesis. Acetate would not replace glucose as principle energy source for Strigomonas oncopelti growing in the minimal defined medium, but when ${ }^{14} \mathrm{C}$-labelled acetate was added to a culture growing in this medium it became diluted with ${ }^{12} \mathrm{C}$-acetate produced from glucose and was utilized for synthesis. To investigate the pathways by which such utilization occurred tracer amounts of labelled acetate were added to cultures in the logarithmic phase of growth; growth was allowed to continue for a further 
two to three generations after which the organisms were harvested, washed and fractionated as described.

Distribution of ${ }^{14} \mathrm{C}$ from acetate in the major cell fractions. Table 2 summarizes the results of typical experiments in which either ${ }^{14} \mathrm{CH}_{3} \mathrm{COOH}$ or $\mathrm{CH}_{3}{ }^{14} \mathrm{COOH}$ was used and shows that acetate was utilized for the synthesis of all the major classes of cellular compounds. The radioactivity of the cold-TCA-soluble material (fraction 1) was found mainly in free amino acids and some peptides; small amounts of labelled uracil were also found in this fraction.

\section{Table 2. Distribution of acetate-derived carbon in the major cell fraction of Strigomonas oncopelti}

Organisms were grown for $\mathbf{2 4} \mathrm{hr}$. in minimal defined medium supplemented with tracer amounts of either ${ }^{16} \mathrm{CH}_{3} \mathrm{COONa}$ or $\mathrm{CH}_{3}{ }^{14} \mathrm{COONa}$ before being fractionated as described in the text. Radioactivity of fractions is expressed as \% total radioactivity fixed by whole organisms.

\section{Fraction*}

1. Cold TCA soluble

2. Ethanol soluble protein

3. Lipid

4. Nucleic acid

5. Protein

$\%$ recovery

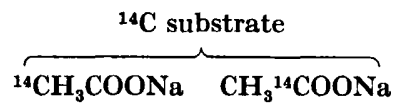

$\%$ total fixed radioactivity

$\begin{array}{rr}4 & 5 \\ 3 & 4 \\ 52 & 45 \\ 3 & 3 \\ 35 & 39 \\ 97 & 96\end{array}$

* See text, p. 710 .

About $50 \%$ of the radioactive material synthesized by the organisms from acetate was extracted by $75 \%(\mathrm{v} / \mathrm{v})$ ethanol in water. Ether extraction separated the ethanol-soluble material into protein (fraction 2) and lipid (fraction 3) which contained most of the radioactivity. The nitrogenous constituents of the lipid fraction, separated after hydrolysis by chromatography, have been identified as serine and ethanolamine; no choline was detected by the phosphomolybdic acid method of Chargaff, Levine \& Green (1948). These nitrogenous compounds contained no carbon derived from acetate.

Chromatograms of the hydrolysed hot-TCA-soluble fraction showed that ${ }^{14} \mathrm{C}$ derived from acetate was located only in the pyrimidines, cytosine, uracil and thymine.

Examination of the hydrolysed protein (fraction 5) by paper chromatography showed that both the methyl and carboxyl carbons of acetate were utilized in the synthesis of the following 13 amino acids : glutamic and aspartic acids, alanine, threonine, histidine, tyrosine, lysine, arginine, valine, proline, phenylalanine, leucine, isoleucine. No ${ }^{14} \mathrm{C}$ was detected in serine, glycine, cysteic acid or methionine, but the latter compound had been added to the growth medium. The same distribution of radioactivity was found in the amino acids of the ethanol-soluble protein (fraction 2). Table 3 summarizes the amounts of radioactivity found in various amino acids determined after their elution from two-dimensional chromatograms of protein hydrolysates; the results are expressed as $\%$ of the activity of glutamic acid. The relative pro- 
portions of some of the amino acids in the protein of Strigomonas oncopelti were estimated by the method of Abelson (1955) using ${ }^{14} \mathrm{C}$ randomly-labelled glucose and also by quantitative ninhydrin estimations (Cocking \& Yemm, 1954). By using these values it is possible to calculate the relative specific activities of the amino acids labelled from acetate; these values are recorded in Table 3.

\section{Table 3. Distribution of acetate-derived carbon in the amino acids of Strigomonas oncopelti}

The protein fraction from organisms grown for $24 \mathrm{hr}$. in minimal defined medium supplemented with ${ }^{14} \mathrm{C}$-labelled acetate was hydrolysed and the amino acids liberated were separated by two-dimensional chromatography. Amino acids were eluted from chromatograms for radioactivity determinations and the relative molar abundance of each was determined by quantitative ninhydrin estimations (Cocking $\&$ Yemm, 1954) or by the method of Abelson (1955). Results are expressed as activity, specific activity or molar abundance relative to 100 for glutamic acid in each case.

\begin{tabular}{|c|c|c|c|c|}
\hline \multirow[b]{2}{*}{ Amino acid } & \multirow[b]{2}{*}{$\begin{array}{c}\text { Relative } \\
\text { activity }\end{array}$} & \multicolumn{2}{|c|}{$\begin{array}{c}\text { Relative molar } \\
\text { abundance determined } \\
\text { by }\end{array}$} & \multirow{2}{*}{$\begin{array}{l}\text { Relative } \\
\text { specific } \\
\text { activity }\end{array}$} \\
\hline & & $\begin{array}{l}\text { Abelson's } \\
\text { method }\end{array}$ & $\begin{array}{l}\text { Ninhydrin } \\
\text { estimation }\end{array}$ & \\
\hline Glutamic acid & 100 & 100 & 100 & 100 \\
\hline Arginine & 63 & 60 & 一 & 105 \\
\hline Aspartic acid & 48 & 73 & 72 & 66 \\
\hline Proline & 37 & 31 & $\mathbf{3 7}$ & 110 \\
\hline Valine & 34 & 68 & 62 & 52 \\
\hline Lysine & $\mathbf{3 4}$ & 60 & - & 56 \\
\hline Phenylalanine* & 29 & - & - & - \\
\hline Threonine & 18 & 29 & 27 & 64 \\
\hline Tyrosine* & 15 & - & - & - \\
\hline Alanine & 8 & 80 & 85 & 10 \\
\hline Histidine* & 6 & 一 & - & 一 \\
\hline Leucine + Isoleucine* & 71 & - & - & 一 \\
\hline Glycine & $\mathbf{0}$ & 一 & 62 & $\mathbf{0}$ \\
\hline Serine & 0 & 一 & 52 & $\mathbf{0}$ \\
\hline
\end{tabular}

* Values for the relative molar abundance of phenylalanine, leucine and isoleucine were not determined because a clear-cut chromatographic separation of these amino acids was not obtained with the solvent systems used. Values for the tyrosine and histidine content of protein are not included as these amino acids are subject to destruction during hydrolysis.

Utilization of randomly-labelled ${ }^{14} \mathrm{C}$ amino acids. In experiments designed to study the uptake of radioactive amino acids, organisms were grown in minimal defined medium supplemented with trace amounts $(1 \mu \mathrm{g} . / \mathrm{ml}$. or less $)$ of the given ${ }^{14} \mathrm{C}$-labelled amino acid. Table 4 shows the distribution of radioactivity from a number of amino acids in the various cell fractions. In most cases the majority of the radioactivity was found in the protein. Glycine and serine contributed appreciable amounts of ${ }^{14} \mathrm{C}$ to the nucleic acid fraction and the addition of ${ }^{12} \mathrm{C}$-adenine or guanine to the growth medium in the presence of ${ }^{14} \mathrm{C}$-glycine decreased the incorporation of radioactivity into the nucleic acid. Radioactivity from glycine and serine was also incorporated into the nitrogenous constituents of the lipid fraction. Chromatographic examination of the protein hydrolysates obtained from these experiments gave some indication of 
Table 4. Distribution of ${ }^{14} \mathrm{C}$ from randomly-labelled amino acids among cellular fractions of Strigomonas oncopelti

Organisms were grown for $\mathbf{2 4} \mathrm{hr}$. in minimal defined medium supplemented with tracer amounts of ${ }^{14} \mathrm{C}$-labelled amino acids. Cell fractionation was carried out as described in the text (p. 710). Radioactivity of fractions is expressed as a percentage of the total radioactivity fixed by whole organisms.

${ }^{14} \mathrm{C}$-labelled amino acid added to minimal medium

Fraction Glutamic Aspartic Glycine Glycine* Serine Leucine Valine $\begin{gathered}\text { Argi- } \\ \text { nine }\end{gathered}$

$\begin{array}{lrrrrrrrr}\begin{array}{l}\text { 1. Cold TCA } \\ \text { soluble }\end{array} & 5 & 4 & 5 & 6 & 9 & 1 & 3 & 6 \\ \begin{array}{l}\text { 2. Ethanol- } \\ \text { soluble protein }\end{array} & \mathbf{6} & \mathbf{5} & \mathbf{2} & \mathbf{5} & \mathbf{4} & \mathbf{1 0} & \mathbf{8} & \mathbf{5} \\ \text { 3. Lipid } & \mathbf{1 2} & \mathbf{1 2} & \mathbf{6} & \mathbf{7} & \mathbf{1 5} & \mathbf{0 \cdot 5} & \mathbf{0 \cdot 5} & \mathbf{2} \\ \text { 4. Nucleic acid } & \mathbf{1 0} & \mathbf{8} & \mathbf{3 8} & \mathbf{1 6} & \mathbf{1 2} & \mathbf{0 \cdot 5} & \mathbf{0 \cdot 5} & \mathbf{2} \\ \text { 5. Protein } & \mathbf{5 9} & \mathbf{5 8} & \mathbf{4 5} & \mathbf{6 0} & \mathbf{5 1} & \mathbf{7 8} & \boldsymbol{7 7} & \mathbf{8 3} \\ \quad \text { \% recovery } & \mathbf{9 1} & \mathbf{8 7} & \mathbf{9 6} & \mathbf{9 4} & \mathbf{9 1} & \mathbf{9 0} & \mathbf{8 9} & \mathbf{9 8}\end{array}$

* In this experiment ${ }^{12} \mathrm{C}$ adenine $(20 \mu \mathrm{g} . / \mathrm{ml}$.) was added to the minimal synthetic medium in addition to ${ }^{14} \mathrm{C}$-labelled glycine.

\section{Table 5. Interconversion of amino acids by Strigomonas oncopelti}

Organisms were grown for $24 \mathrm{hr}$, in minimal defined medium supplemented with tracer amounts of randomly-labelled ${ }^{14} \mathrm{C}$ amino acids. Protein fractions of organisms were hydrolysed and chromatographed and radioautographs prepared from the chromatograms. The distribution of radioactivity on radioautographs is recorded:,,$+++(+)$, and - , represent very strong, strong, weak and no detectable labelling, respectively.

${ }^{14} \mathrm{C}$-labelled amino acid added to minimal medium

Amino acids in protein hydrolysate

Cysteic acid

Aspartic acid

Glutamic acid

Serine

Glycine

Threonine

Alanine

Tyrosine

Histidine

Lysine

Arginine

Proline

Valine

Phenylalanine

Leucine + Isoleucine

Aspartic Glutamic Glycine Serine Leucine Valine Arginine

Relative degrees of ${ }^{14} \mathrm{C}$-labelling of amino acids in protein hydrolysate

\begin{tabular}{ccccccc}
\hline & - & + & + & - & - & - \\
+ & + & - & - & - & - & - \\
+ & ++ & - & - & - & - & $(+)$ \\
- & - & + & + & - & - & - \\
- & - & + & + & - & - & - \\
+ & + & - & - & - & - & - \\
+ & + & - & - & - & - & - \\
+ & + & - & - & - & - & - \\
+ & + & - & - & - & - & - \\
+ & + & - & - & - & - & - \\
+ & ++ & - & - & - & - & + \\
+ & ++ & - & - & - & - & $(+)$ \\
+ & + & - & - & - & + & - \\
+ & + & - & - & - & - & - \\
+ & + & - & - & + & + & -
\end{tabular}

the ability of Strigomonas oncopelti to interconvert amino acids; the qualitative data obtained in this way are summarized in Table 5. An exogenous supply of ${ }^{14} \mathrm{C}$-labelled glutamic acid was utilized by $S$. oncopelti for the synthesis of 12 amino acids and of these arginine and proline were found to have the same 
specific activity as the glutamic acid residues of the protein. On the other hand, radioactivity from ${ }^{14} \mathrm{C}$-arginine was found almost entirely in the corresponding amino acid of the cell protein indicating that there was no appreciable conversion to glutamic acid, proline or other amino acids. The use of ${ }^{14} \mathrm{C}$-glycine or serine showed that these two amino acids are readily interconverted by $S$. oncopelti and that they both contribute ${ }^{14} \mathrm{C}$ to cysteine, detected on chromatograms as cysteic acid. Exogenous ${ }^{14} \mathrm{C}$-valine contributed carbon to leucine but the addition of ${ }^{14} \mathrm{C}$ leucine showed that the reverse reaction did not occur.

Utilization of labelled materials for nucleic acid synthesis. Table 6 summarizes the results of a number of experiments in which several ${ }^{14} \mathrm{C}$-labelled substrates were used. With the exception of randomly-labelled glucose, which contributed carbon to all the components of nucleic acid, these compounds fall into two groups; the first group specifically labels purines, and includes glycine, serine and guanine; the second group labels pyrimidines and includes acetate, aspartic and glutamic acids and uracil. Thymine was not utilized by Strigomonas oncopelti.

\title{
Table 6. Utilization of ${ }^{14} \mathrm{C}$-labelled compounds for nucleic acid synthesis by Strigomonas oncopelti
}

\begin{abstract}
Organisms were grown for $24 \mathrm{hr}$. in minimal defined medium supplemented with tracer amounts of ${ }^{14} \mathrm{C}$-labelled compounds. Nucleic acid fractions of organisms were hydrolysed and chromatographed, and radioautographs of the chromatograms prepared. The distribution of radioactivity on radioautographs is recorded :,$+(+)$, and - represent strong, weak and no detectable labelling respectively.
\end{abstract}

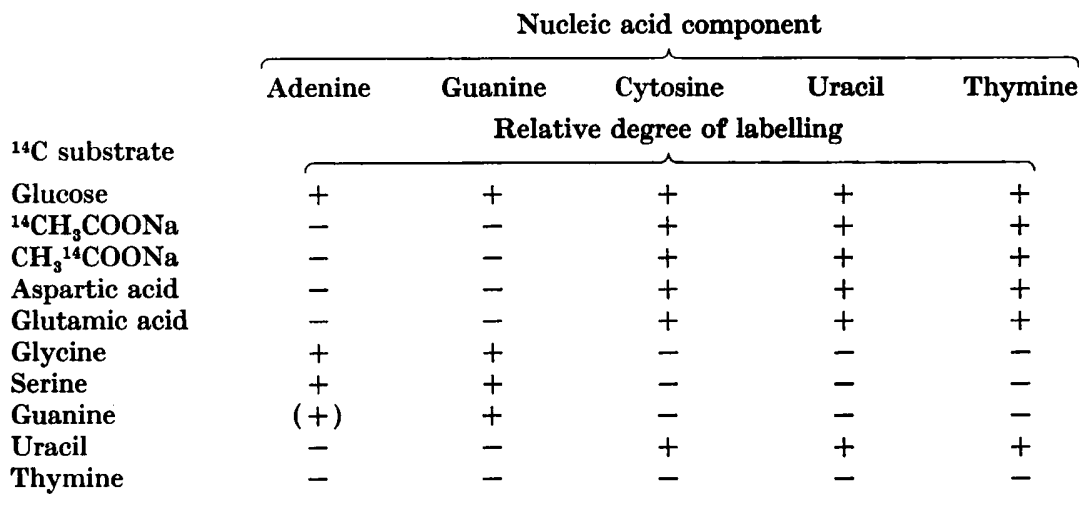

\section{DISCUSSION}

The data obtained from isotope incorporation experiments and from studies of the nutritional requirements of Strigomonas oncopelti permit some conclusions to be drawn concerning the biosynthetic pathways which function in this organism when it is growing in the simple defined medium used. The carbon of glucose and acetate can be utilized for the biosynthesis of all the amino acids except methionine, glycine, serine and cysteine. The work of a number of investigators (reviewed by Stekol, 1955) concerning the precursors 
of methionine allows the formulation of a pathway for methionine synthesis as follows:

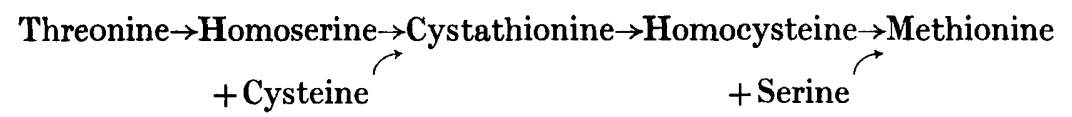

That this pathway may be operating in $S$. oncopelti is suggested by the fact that serine + threonine + cysteine replace methionine in the defined growth medium and also that methionine may be replaced by cystathionine or by homocysteine + serine. Furthermore, this pathway appears to be reversible in $S$. oncopelti since acetate carbon was not detected in glycine or serine and the requirement of this organism for these two amino acids is met by methionine.

The results concerning purine and pyrimidine synthesis in Strigomonas oncopelti are in keeping with the relationships worked out for other organisms; purine synthesis involves the utilization of glycine and pyrimidine synthesis the utilization of aspartic acid. However, $S$. oncopelti differs from all other trypanosomid flagellates which have so far been studied in its ability to synthesise the purine nucleus. Thus Crithidia fasciculata (Nathan \& Cowperthwaite, 1954), Trypanosoma cruzi (Citri \& Grossowicz, 1955), T. rhodesiense (Williamson \& Rollo, 1952) and T. mega (Bone \& Steinert, 1956) appear to be incapable of synthesizing the purine ring.

The general pattern of results obtained from incorporation studies with ${ }^{14} \mathrm{CH}_{3} \mathrm{COOH}$ and $\mathrm{CH}_{3}{ }^{14} \mathrm{COOH}$ is similar to that reported by McQuillen \& Roberts (1954), who studied the utilization of acetate by Escherichia coli. In $E$. coli acetate is utilized by three main pathways. One pathway leads to incorporation of acetate carbon into lipid, another to incorporation into leucine and by the third acetate enters the Krebs tricarboxylic acid cycle and contributes to the group of products derived from aspartic and glutamic acids. All these pathways would appear to function in Strigomonas oncopelti, and in addition acetate carbon is utilized for the synthesis of alanine, histidine, valine and the aromatic amino acids tyrosine and phenylalanine. Calculation of the specific radioactivities of the amino acids labelled with carbon derived from acetate throws some light on the inter-relationships between them. The specific activities of glutamic acid, arginine and proline are very nearly equal, suggesting a relationship between these amino acids in that they derive the same number of carbon atoms from acetate. There appears to be a similar relationship between aspartic acid and threonine. Furthermore, it was found that glutamic acid, arginine and proline had considerably higher specific activities than aspartic acid, threonine and lysine; as pointed out by McQuillen \& Roberts (1954) for the case of Escherichia coli, this must be interpreted in terms of a tricarboxylic acid cycle rather than a dicarboxylic: acid cycle involving the condensation of acetate to succinate, as the latter mechanism would result in the aspartic acid group having a higher specific activity than the glutamic acid group.

The lack of suitable defined growth media for parasitic flagellates may explain the fact that there have, as yet, been no other detailed studies of the biosynthetic capabilities of such organisms. Nevertheless, further work along 
these lines need not necessarily await the development of completely defined growth media as shown by the recent work of Grant \& Fulton (1956) who studied the incorporation of ${ }^{14} \mathrm{C}$-labelled glucose into the cellular components of Trypanosoma rhodesiense maintained in a salts + glucose + serum medium, and also by the work of Boné \& Steinert (1956) who demonstrated the incorporation of adenine into nucleic acid and carbon from glycine and formate into protein of $T$. mega growing in a relatively complex medium.

\section{REFERENCES}

Abelson, P. H. (1955). Studies of biosynthesis in Escherichia coli. Publ. Carneg. Instn, no. 607, p. 28.

BonÉ, G. J. \& Steinert, M. (1956). Isotopes incorporated in the nucleic acids of Trypanosoma mega. Nature, Lond. 178, 308.

Chargaff, E., Levine, C. \& Green, C. (1948). Techniques for the demonstration by chromatography of nitrogenous lipid constituents, sulfur-containing amino acids, and reducing sugars. J. biol. Chem. 175, 67.

CrTri, N. \& Grossowicz, N. (1955). A partially defined culture medium for Trypanosoma cruzi and some other haemoflagellates. J. gen. Microbiol. 13, 273.

Clausen, J. K. (1955). Observations on the carbohydrate metabolism of the flagellate Strigomonas oncopelti. J. gen. Microbiol. 12, 496.

Cocking, E. C. \& Yemm, E. W. (1954). Estimation of amino acids by ninhydrin. Biochem. J. 58, xii.

GLadstone, G. P. (1937). The nutrition of Staphylococcus aureus; nitrogen requirements. Brit. J. exp. Path. 18, 322.

Grant, P. T. \& Fulton, J. D. (1956). Glucose catabolism by strains of Trypanosoma rhodesiense. Biochem. J. 63, 8 P.

Lwoff, M. (1937). Aneurin as a growth factor for the trypanosomid flagellate Strigomonas oncopelti. C.R. Soc. Biol., Paris, 126, 771.

McQuillen, K. \& RoBerTs, R. B. (1954). The utilization of acetate for synthesis in Escherichia coli. J. biol. Chem. 207, 81.

Nathan, H. A. \& Cowperthwaite, J. (1954). Use of the trypanosomid flagellate, Crithidia fasciculata, for evaluating antimalarials. Proc. Soc. exp. Biol., N.Y. 85, 117 .

Nathan, H. A., Cowperthwaite, J., Carsted, K. W. \& Hutner, S. H. (1955). In Biochemistry and Physiology of Protozoa. Ed. Hutner, S. H. \& Lwoff, A., vol. 2, p. 35. New York: Academic Press Inc.

Newton, B. A. (1956a). A synthetic growth medium for the trypanosomid flagellate Strigomonas (Herpetomonas) oncopelti. Nature, Lond. 177, 279.

Newron, B. A. $(\mathbf{1 9 5 6} b)$. Biosynthetic capabilities of the parasitic flagellate Strigomonas (Herpetomonas) oncopelti. J. gen. Microbiol. 15, viii.

Noguchi, H. \& Tilden, E. B. (1926). Comparative studies of Herpetomonads and Leishmanias. J. exp. Med. 44, 307.

RYLEY, J. F. (1955). Studies on the metabolism of the protozoa. 4. Metabolism of the parasite flagellate Strigomonas oncopelti. Biochem. J. 59, 353.

Stekol, J. A. (1955). Synthetic pathways of methionine, cysteine, and threonine. In A Symposium on Amino Acid Metabolism, p. 509. Ed. McElroy, D. W. \& Glass, B. H. Baltimore: The Johns Hopkins Press.

Williamson, J. \& Rollo, I. M. (1952). Stimulating effect of amino acids on the survival at $37^{\circ} \mathrm{C}$ of $\mathrm{Trypanosoma}$ rhodesiense in a serum-free synthetic medium. Nature, Lond. 170, 376.

(Received 2 July 1957) 